\title{
From child-robot interaction to child-robot-therapist interaction: A case study in autism
}

\author{
I. Giannopulu ${ }^{\mathrm{a}, *}$ and G. Pradel ${ }^{\mathrm{b}}$ \\ ${ }^{a}$ Catholic University of Paris, Paris-France, CUP-EPP, 23 rue de Montparnasse, Paris, France \\ ${ }^{\mathrm{b}}$ Laboratory of Computer Science, Integrative Biology and Complex Systems, IBISC FRE CNRS Rue du Pelvoux \\ Evry Cedex-France, University of Evry-Genopole, Paris, France
}

\begin{abstract}
Troubles in social communication as well as deficits in the cognitive treatment of emotions are supposed to be a fundamental part of autism. We present a case study based on multimodal interaction between a mobile robot and a child with autism in spontaneous, free game play. This case study tells us that the robot mediates the interaction between the autistic child and therapist once the robot-child interaction has been established. In addition, the child uses the robot as a mediator to express positive emotion playing with the therapist. It is thought that the three-pronged interaction i.e., child-robot-therapist could better facilitate the transfer of social and emotional abilities to real life settings. Robot therapy has a high potential to improve the condition of brain activity in autistic children.
\end{abstract}

Keywords: Robot, autism, interaction, rehabilitation, social and emotion behaviour

\section{Introduction}

In typical developing infants, cognitive and emotional attitudes towards objects and people constitute the ingredients of social relationships. Infantile autism, which is a neurodevelopmental disorder, is characterised by difficulties in social and interpersonal communication as well as in processing own and other people's emotions [20]. Emotional impairment is thought to be a consequence of deficits in "theory of mind" i.e., ToM (e.g., [7]). The ToM deficit is associated with processing of non-verbal sounds [10], human voices [8], touching [21], eye contact [17] and facial information $[1,6]$. Individuals with autism often exhibit impaired processing of emotions [14] mani-

*Corresponding author: Irini Giannopulu, Catholic University of Paris, Paris-France, CUP-EPP, 23 rue de Montparnasse, 75006 Paris, France. E-mail: igiannopulu@psycho-prat.fr. fested in the form of increased stress and anxiety [5, 15]. As a result, children with autism regularly engage in stereotyped ritualistic behaviours and have difficulties initiating activities to share interests and cooperate with others. They appear to have a restricted range of interests; their thinking and behaviour is rigid [21].

As would be expected, a large number of functional neuroimaging studies have demonstrated that brain regions involved in the processing of emotions are implicated in the clinical neuropsychology of autism. In particular, these studies show that the neural substrate underlying emotional impairment involves the amydgala [16], the superior temporal sulcus and gyrus as well as the orbital frontal cortex [12]. In addition, autistic children also show aberrant brain connectivity and disruption of white matter tracts between temporal regions [21] which disrupt acquisition, consolidation as well as social interaction $[1,2,26]$. Taken together, the aforementioned studies provide the basis for con- 
cluding that in autism the more impaired cortical areas are those that are involved in complex cognitive functions such as perception, social interaction and emotion.

In autism rehabilitation therapy, different approaches are currently being utilised to better understand the capacity of autistic children for social and emotional interaction. These approaches are based on the belief that artificial environments i.e., robots, seem to be more helpful than real environments in allowing autistic children to express social interest; this in turn could lead to development of their social skills $[18,19]$. One of these approaches is to simplify the elements that constitute the interaction. In order to study effectively the robot-child interaction, researchers have used fixed $[9,18,19$, $25,28,34]$ for example or mobile [19, 22-24, 31] robots. Regardless of the child's mental age, all these studies have reported dyadic interaction between the autistic child and the robot. Even though (because of the pathology) the number of the children participating in these experiments is limited, the dyadic child-robot interaction is reflected in attention [19], imitation cognition [27] visual contact [9], touching [28], manipulating and posture [19]. In the aforementioned studies, the focal point of the analysis was on a single mode of interaction. As far as we know, only two studies have reported multimodal interactions in dyadic relationships i.e., between the autistic child and a mobile robot in spontaneous free game play [22-24]. They have concluded that mobile robots could be best used as a mediator of social stimuli in order to reduce the impairment of the autistic child's skills [24]. A behavioural proposal of robot-child social interaction has been expounded upon in our recent paper using a mathematical model based on Thom's catastrophe theory [22]. The present study, which is a case study, aims to examine the role of our mobile robot named "GIPY-1" in the context of social and emotional interaction of the autistic child with a third person: the therapist. The three-pronged interaction among the autistic child, the robot and the therapist will be investigated in spontaneous, free game play by means of a multimodal approach. As in our previous papers, the duration time calculation will be considered. We hypothesise that once child-robot interaction is established, the child will use the robot as a mediator to initiate the interaction with the therapist and express emotion.

\section{Method}

\subsection{Case study}

"A" is a right-handed young boy. He exhibits mental retardation as per the international classification of diseases (ICD, 1990). His chronological age is 8 years old and his developmental age is 2 years old. The child was diagnosed with autism when he was 3 years old and still displays all characteristics of autism according to the Diagnostic and Statistical Manual of Disorders IV-TR (2003). In addition, the Childhood Autism Rating Scale [33] has shown severe autism with a score of 43 points. "A" has deficits in reciprocal social interactions and communication (speech and language), stereotyped behaviour and restricted interests and activities. At the time of the experiment he was attending special education classes for autism.

The study was approved by the local Ethical Committee and conforms to the Helsinki convention. The parents were formally informed and agreed to the participation of their child in the study. Anonymity was guaranteed.

The study was conducted in a day hospital. The experiment took place in a room familiar to the child. The therapist who is familiar with the child was present in the room. A digital camera recorded the whole experiment.

\subsection{Material}

\subsubsection{Room}

The room was $4.56 \mathrm{~m}$ by $3.34 \mathrm{~m}$. A chair, a small wardrobe and a table on which the equipment needed for the framework of the study was placed (laptop and joystick), were used. In order to reduce the presence of disruptive elements and so as to avoid autistic bend, the room was left bare [30].

\subsubsection{Robot}

A mobile robot, called "GIPY-1", which is cylindrical-shaped with a diameter of $20 \mathrm{~cm}$ and a height of $30 \mathrm{~cm}$ was used. A representation of a neutral facial expression constitutes the cladding of the robot: the round eyes and nose triangle were dyed olive green and the elliptical mouth was dyed red (Fig. 1). Everything was covered with a transparent plastic sheet. The simplicity of the robot was driven by the preference of autistic children for simple and predictable toy design [29]. An operator manipulated the robot via a wireless 


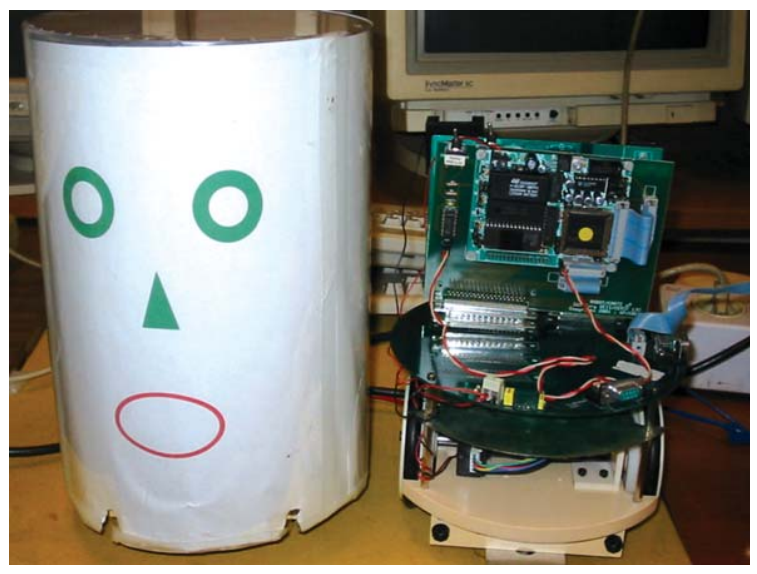

Fig. 1. GIPY 1.

remote control using a joystick connected to a laptop. The robot could move forward, backward and turn on itself at low speed. These movements were constant.

\subsubsection{Protocol}

The duration of the session was 5 minutes. The robot was placed on the ground beforehand, in the centre of the room, its stylised face toward the entrance. The game play session began as follows: when the child and the therapist entered the room, the tele-operated robot carried out three movements (move forward, move back, $360^{\circ}$ swivel). As in real social interaction, the child and the robot altered their responses. If the child approached, the robot moved back and conversely. If the child moved away from the robot, i.e., ignored the robot, the robot followed the child in order to attract his attention. If the child remained motionless, the robot approached or turned itself around in order to focus the attention of the child. All movements were standardised.

\subsubsection{Analysis}

Two independent judges unfamiliar with the aim of the study completed the observations of the game play skills. Both performed the analyses of video sequences with Elan software. Prior to assessing game play improvement, inter-judge reliability was assessed to ensure that both judges who analysed videotapes were consistent in their analyses. Inter-judge reliability was assessed using intra-class coefficients to make the comparison between them. The inter-judge reliability was good (Cohen's kappa $=0.63)$.
The dependant variable was the time of child-robot interaction and child-robot-therapist. Accordingly, we calculated the duration time of all the characteristics of each criterion. This was defined as the duration between the onset time and the offset time of each child's behaviour toward the robot. Five criteria were defined. These criteria were: 1 ) eye contact (looking at the robot), 2) touch (touching the robot without manipulating it), 3) manipulation (operating the robot), 4) posture (changing corporal position toward the robot) and 5) positive emotion (display of enjoyment). The duration of each criterion was calculated in seconds and was considered independently of the others. Concerning, for example, the characteristic "s/he looks at the immobile robot" ("eye contact") the onset time corresponded to the time when the child looked at the robot and the offset time to the moment when the child looked away from the robot. We calculated the duration of all the characteristics of each criterion. We summed up the duration corresponding to each criterion. Only the total duration is presented in the results section.

\section{Results}

Table 1 gives the characteristics of each criterion identified in game play of child-robot interaction and child-robot-therapist interaction.

A schematic representation of duration time of childrobot interaction and child-robot-therapist interaction is given in Fig. 2. The mean time of child-robot interaction is $25 \mathrm{sec}$; the mean time of child-robot-therapist interaction is $30 \mathrm{sec}$. In other words, the child spends half the time playing with the robot and the half the time playing with the robot and the therapist.

The duration time of child-robot interaction and child-robot-therapist interaction is presented in Fig. 3. The duration time of "eye contact" and of "touch" is similar in both situations. However the duration time of "manipulation", of "posture" and of "positive emotion" differ between the two situations. As we can observe, positive emotion is more easily expressed when the child interacts with the therapist and the robot than when the child interacts only with the robot. This difference, reflective of the changes in autistic child behaviour with the robot over a period of time also tells us that a mobile robot could be used as a mediator for social and emotional interaction. This is an encouraging conclusion with regard to the potential of human-to-human interaction. 
Table 1

Characterization for each criterion

\begin{tabular}{|c|c|c|c|c|}
\hline Touch & Eye contact & Manipulating & Posture & Positive emotion \\
\hline $\begin{array}{l}\text { he puts the left hands on } \\
\text { the robot OR the } \\
\text { therapist }\end{array}$ & $\begin{array}{l}\text { he looks at the immobile } \\
\text { robot OR therapist }\end{array}$ & $\begin{array}{l}\text { he seizes and blocks the } \\
\text { robot with the two } \\
\text { hands }\end{array}$ & $\begin{array}{l}\text { he sits downs in front of } \\
\text { robot }\end{array}$ & he smiles to the therapist \\
\hline $\begin{array}{l}\text { he puts the right hand on } \\
\text { the robot OR on the } \\
\text { therapist }\end{array}$ & $\begin{array}{l}\text { he watches the robot } \\
\text { turning }\end{array}$ & he lifts of the robot & $\begin{array}{l}\text { he bends towards the } \\
\text { robot AND/OR the } \\
\text { therapist }\end{array}$ & he laughs to the therapist \\
\hline \multirow{3}{*}{$\begin{array}{l}\text { he touches the robot OR } \\
\text { the therapist with both } \\
\text { hands }\end{array}$} & he watches the therapist & $\begin{array}{l}\text { he stops the robot with } \\
\text { both hands }\end{array}$ & he bends over the robot & $\begin{array}{l}\text { he expresses friendliness } \\
\text { to the therapist }\end{array}$ \\
\hline & $\begin{array}{l}\text { he watches the robot } \\
\text { going away } \\
\text { he watches the robot } \\
\text { approaching }\end{array}$ & $\begin{array}{l}\text { he catches the robot } \\
\text { AND/OR the therapist } \\
\text { he returns the robot }\end{array}$ & $\begin{array}{l}\text { he squats and bends over } \\
\text { the robot } \\
\text { he steps over the robot }\end{array}$ & $\begin{array}{l}\text { he expresses tenderness to } \\
\text { the therapist } \\
\text { he looks happy with the } \\
\text { therapist }\end{array}$ \\
\hline & & $\begin{array}{l}\text { he tilts the robot around } \\
\text { itself and looks of its } \\
\text { wheel } \\
\text { he puts back the robot } \\
\text { upright }\end{array}$ & & $\begin{array}{l}\text { he looks pleased to the } \\
\text { therapist }\end{array}$ \\
\hline
\end{tabular}

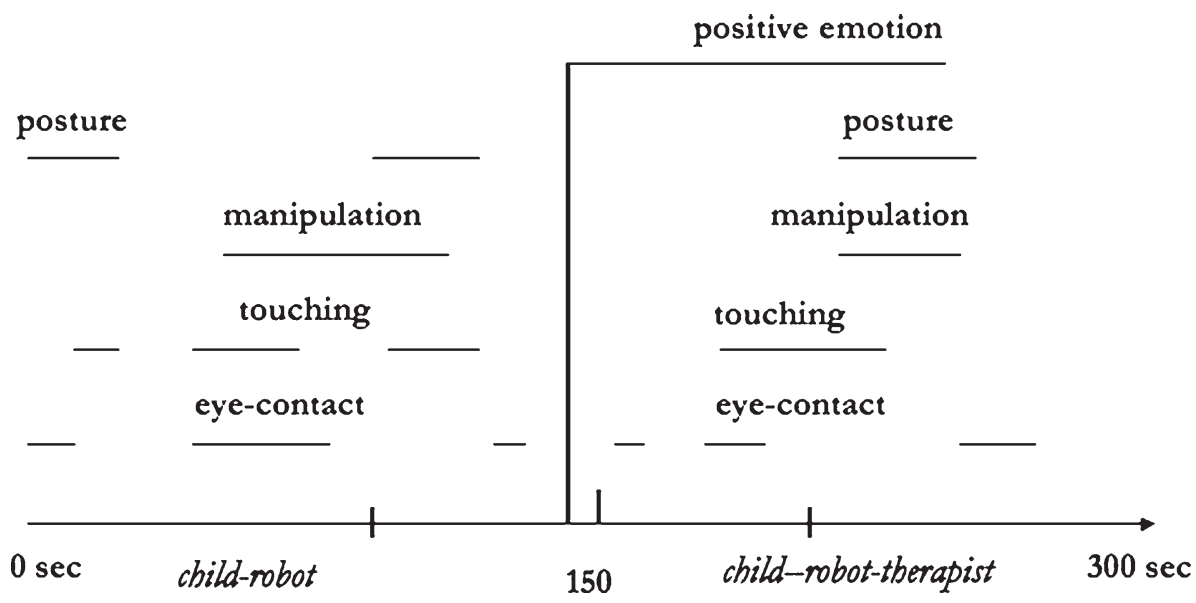

Fig. 2. Schematic representation of child-robot interaction and child-robot-therapist interaction.

\section{Discussion}

In this case study, we analysed the ingredients of child-robot two-pronged interaction and child-robottherapist three-pronged interaction. Consistent with our hypothesis, the child first establishes a relationship with the robot and then uses the robot as an "instrument" to initiate the interaction with the therapist. At first glance, our results are compatible with recent findings according to which artificial environments i.e., presence of a robot, are more effective than real environments in allowing autistic children to express social interest towards the robot $[9,18,19,25,28,34]$. In these studies, researchers have used robots for treating autistic children. However, the relationship between robot and child has been studied solely based on the analysis of a single mode of interaction. Furthermore, the studies have been conducted using fixed robots. Our results go beyond these findings because we have demonstrated, as far we know for the first time, that in spontaneous, free game play, an autistic child uses the robot to interact with the therapist and to express positive emotion. As such, on the one hand, we have shown that the child-robot interaction is based on a cognitive state and, on the other, that the child uses the robot as a mediator to express positive emotion playing with the therapist.

More precisely, in our study, the interaction between robot and child was analysed using different criteria such as eye contact (looking at the robot), manipu- 


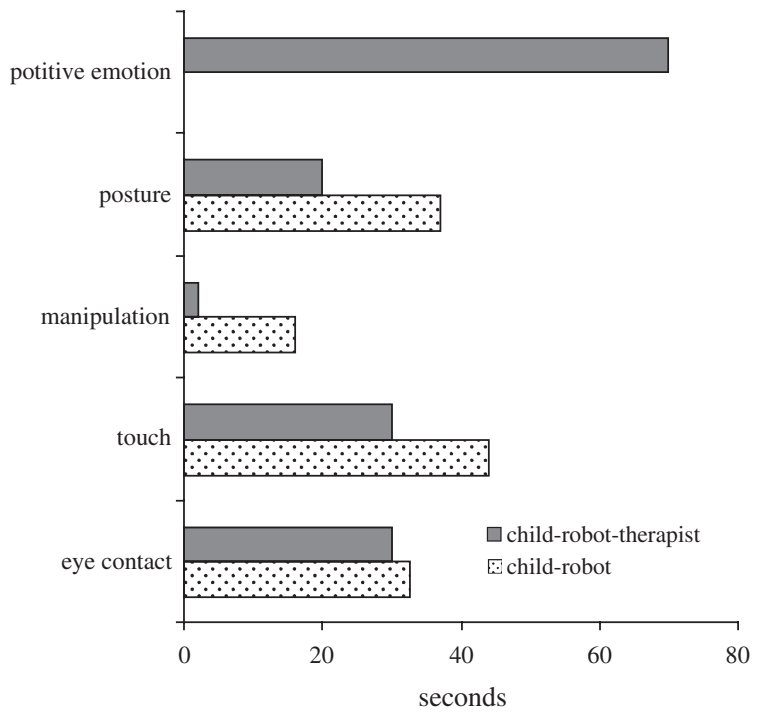

Fig. 3. Total duration time of child-robot interaction and child-robottherapist interaction following each criterion.

lating (operating with the robot), touch (touching the robot without manipulating it), posture (changing postural position toward the robot). Consistent with our previous studies [22-24], we have demonstrated that visual, haptic, tactile perception and posture, i.e., multimodal perception, are on the basis of the interest the child displays towards the robot. This is because, in our approach (as in [32]), perception and cognition are considered to be a single domain rather than two distinct entities. The criteria we have chosen are assumed to represent the state of the child's cognitive processes, as expressed by the interest the child exhibits towards the robot in spontaneous, free game play [24]. As our case study has shown, once this state is established, the child develops a triadic relation i.e., with the robot and the therapist, thereby displaying enjoyment, which is a positive emotion. The expression of positive emotion could be related to the emergence of a cognitive state, which is multimodal in our case. This expression appears when the child interacts with the therapist using the robot. This is not the case when the child interacts with the robot only. This is a very important finding when we consider that the subject of our case study "A" exhibited a score of 43 which corresponds to severe autism. Individuals with severe autism exhibit very limited social skills. They don't express emotions. They don't respond well to behavioural therapy and in fact tend to show few, if any sign of improvement after such therapy is undertaken. However, as we showed in our case study, "A" is in constant interaction with the robot, expressed by a multimodal cognitive state which, according to us, allows him to express positive emotion with the therapist. This is an objective observation, rendered by two independent judges unfamiliar with the aim of the study.

Based on the investigation of a single individual to explore causation, this case study is an instructive example which provides a systematic way of looking at events. It lends itself to both testing and generating hypotheses.

Considering the above, it would be fair to conclude that autism therapy using robots seems to be effective, safe and convenient. What is important is the "passage" from child-robot interaction to child-robottherapist interaction. When " $A$ " interacts with both the robot and the therapist, he changes his behaviour. What causes this behavioural modification? We think that the robot as a mediator could bring about neuropsychological improvements to the autistic child. As the results have shown, the extent of that improvement seems to be smaller when the child interacts with the robot than when he interacts with the therapist. We believe that the child's reactions to the robot are very important in establishing child interest and are of paramount importance in robot therapy. In fact, this child-robot interaction could be thought of as the building block from which the relationship among humans may be developed. Consistent with this interpretation may be the fact that positive emotion is expressed only when the child interacts with the therapist via the robot. Positive emotion is quasi-absent when the child interacts with the mobile robot on a standalone basis. As such, this study is to our knowledge, one of the first to show that in spontaneous free game play the robot is a tool, which can help autistic children engage in social and emotional interaction with adults. It seems thus reasonable to infer that the three-pronged interaction i.e., child-robot-therapist could better facilitate the transfer of social and emotional abilities to real life.

It is fundamental to think of the robot as a system and consider its usage and design specifically for therapeutic purposes. Clearly the need to investigate the neuropsychological effects on an autistic child before and after the robot therapy session by evaluating the child's neuronal activities is necessary. The current study, which is a case study, allows us to assume that robot therapy might have a high potential for improving the brain activity of child with autism. A new study to investigate this effect more precisely must be 
performed in the future. Further experiments are needed to investigate the repeatability and durability of the effects and the relationship between the functions of the robots and their effects on autistic children as well as with regard to the interaction between the child and the therapist.

The child-robot-therapist interaction is a growing and challenging area, which requires interdisciplinary collaboration among robotic scientists, computer scientists, engineers, and neuropsychologists. We need to build new theories, computational models and methodologies in order to replicate and confirm the scientific findings.

\section{Acknowledgments}

The authors thank ANR for its support. It is possible to find different information concerning the members of RobAutiSTIC as well as the project on http://robautistic.ibisc.univ-evry.fr

\section{References}

[1] R. Adolphs, A. Jansari and D. Tranel, Hemispheric perception of emotional valence from facial expressions, Neuropsychology 15 (2001), 516-524.

[2] R. Adolphs and D. Tranel, Intact recognition of emotional prosody following amygdala damage, Neuropsychologia 37 (1999), 1285-1292.

[3] J.P. Aggleton, The Amygdala: A Functional Analysis, Oxford University Press, (2000).

[4] T. Allison, A. Puce and G. McCarthy, Social perception from visual cues: The role of STS region, Trends of Cognitive Sciences 4 (2000), 267-278.

[5] D.G. Amaral and B.A. Corbett, The amygdala, autism and anxiety, In 2003 Autism: Neural basis and treatment possibilities Wiley Chichester. Novartis Foundation Symposium 251 (2003), 177-197.

[6] C. Ashwin, S. Wheelwright and S. Baron-Cohen, Finding a face in the crowd: Testing the anger superiority effect in Asperger Syndrome, Brain and Cognition 61 (2006), 78-95.

[7] S. Baron-Cohen, A.M. Leslie and U. Frith, Does the autistic child have a theory of mind? Cognition 21 (1985), 37-46.

[8] P. Belin, R.J. Zatorre, A. Lafaille, P. Ahad and B. Pike, Voice selective areas in auditory human cortex, Nature 403 (2000), 309-312.

[9] A. Billard, S. Calinon, R. Dillmann and S. Schaal, Robot programming by demonstration, In B. Siciliano and O. Khatib, editors, Handbook of Robotics, chapter 59. 2008, Springer, 2008 .

[10] N. Boddaert, P. Berm, J.B. Poline, N. Chabanneg, M.C. Mouren-Shneoni, C. Barthelemy, Y. Samson and M. Zilboviciw, Temporal lobe dysfunction in autism: a PET auditory activation study, NeuroImage 13 (2001), S0128.
[11] Y. Bourreau, M. Gonnot, S. Roux and C. Barthélemy, Construction d'une échelle d'évaluation des comportements répétitifs et restreints dans l'autisme (EC2R): Etude préliminaire, Bulletin Scientifique, ARAPI 17 (2006), 62-64.

[12] L. Brothers, The social brain: A project for integrating primate behaviour and neurophysiology in a new domain, Concepts in Neuroscience 1 (1990), 27-51.

[13] F. Castelli, Understanding emotions from standardized facial expressions in autism and normal development, Autism 4 (2005), 428-449.

[14] G. Celani, M.W. Battacchi and L. Arcidiacono, The understanding of the emotional meaning of facial expressions in people with autism, Journal of Autism and Developmental Disorders 29 (1999), 57-66.

[15] B.A. Corbett, A.B. Kantor, H. Schulman, W.L. Walker, L. Lit, P. Ashwood, D.M. Rocke and F.R. Sharp, A proteomic study of serum from children with autism showing differential expression of apolipoproteins and complement proteins, Molecular Psychiatry 12 (2007), 292-306.

[16] B.A. Corbett, V. Carmean, S. Ravizza, C. Wendelken, M.L. Henry, C. Carter and S.M. Rivera, A functional and structura study of emotion and face processing in children with autism, Psychiatry Research 30(173) (2009), 196-205.

[17] E. Courchesne, Event-related potentials: Comparison between children and adults, Science 197 (1977), 589-592.

[18] K. Dautenhahn and I. Werry, Towards interactive robots in autism therapy, Pragmatics \& Cognition 121 (2004), 1-35.

[19] K. Dautenhahn, Socially intelligent robots: Dimensions of human-robot interaction, Philosophical Transaction of the Royal Society B 362 (2007), 679-704.

[20] DSM-IV-TR Manuel diagnostique et statistique des troubles mentaux, Paris, Editions Masson, 2003.

[21] U. Frith and C.D. Frith, Development and neurophysiology of mentalizing, Philosophical Transaction of the Royal Society B Biological Science 358 (2003), 459-473.

[22] I. Giannopulu and G. Pradel, Mobile toy robots can be used in autism therapy: An example of application, IEEE Proceedings in the IROS 2009 paper number SuT8.pdf in the workshop CD Proc. 2009 (2009a).

[23] I. Giannopulu, G. Pradel, Interactions multimodales en situation de jeu libre entre enfants autistes et un robot mobile. $7^{\text {ème }}$ Journée Nationale de la recherche en Robotique. http://jnrr09. lms.sp2mi.univpoitiers.fr/IMG/pdf/Giannopulu_Pradel. Novembre, Domaine de La Grande Garenne 18330 Neuvysur-Barangeon (2009b).

[24] I. Giannopulu and G. Pradel, Multimodal interactions in free game play of children with autism and a mobile robot, $\mathrm{Neu}$ rorehabilitation 27 (2010), 305-311.

[25] C. Kozima and Y. Yasuda, Children-robot interaction: A pilot study in autism therapy, Progress in Brain Research 164 (2007), 385-400.

[26] B.M. Nacewicz, K.M. Dalton, T. Johnstone, M. Long, E.M McAuliff, T.R. Oakes, A.L. Alexander and R.J. Davidson, Amygdala Volume and Nonverbal Social Impairment in Adolescent and Adult Males with Autism http://brainimaging.wa isman.wisc.edu/publications/2006/NacewiczAmygdalaArch GenPsy.pdf, Archives of General Psychiatry 63 (2006), 1417-1428.

[27] J. Nadel, A. Revel, P. Audry and P. Gaussier, Toward communication: first imitation in infants, low-functioning children with autism and robot, Interaction studies: Social Behavior and Communication in Biological and Artificial System 5 (2004), 45-54. 
[28] F. Michaud, T. Salter, A. Duquette and J.F. Laplante, Perspectives on mobile robots used as tools for pediatric rehabilitation, Assistive Technology-Special Issue on Intelligent System in Pediatric Rehabilitation 19 (2007), 14-19.

[29] J. Pedersen and J. Schelde, Behavioral aspects of infantile autism: an ethological description, European Child and Adolescent Psychiatry 6 (1997), 96-100.

[30] P. Planche, E. Lemonnier, K. Moalic, C. Labous and A. Lazartigues, Les modalités de traitement de l'information chez les enfants autistes, Annales Médico-Psychologiques 160 (2002), 559-564.

[31] G. Pradel and I. Giannopulu, Generating interactions in autism spectrum disorders by means of a mobile robot, International Journal of Social Robots (in review) (2009).
[32] P.C. Quinn and P.D. Eimas, The emergence of category representations during infancy: Are separate perceptulal and conceptual processes required? Journal of Cognition and Development 1 (2000), 55-61.

[33] E. Schopler, R.J. Reichler, R.F. De Vellis and K. Daly, Toward objective classification of childhood autism: Childhood Autism Rating Scale (CARS), Journal of Autistic Development Disorders 10 (1980), 91-103.

[34] Y. Yokoyama, The Possibility of the Psychiatric Treatment with a Robot as an Intervention -From the Viewpoint of Animal Therapy- (2002), Proc. of Joint 1st International Conference on Soft Computing and Intelligent Systems and 3rd International Symposium on Advanced Intelligent Systems paper number 23Q1-1, in CD-ROM Proc. 

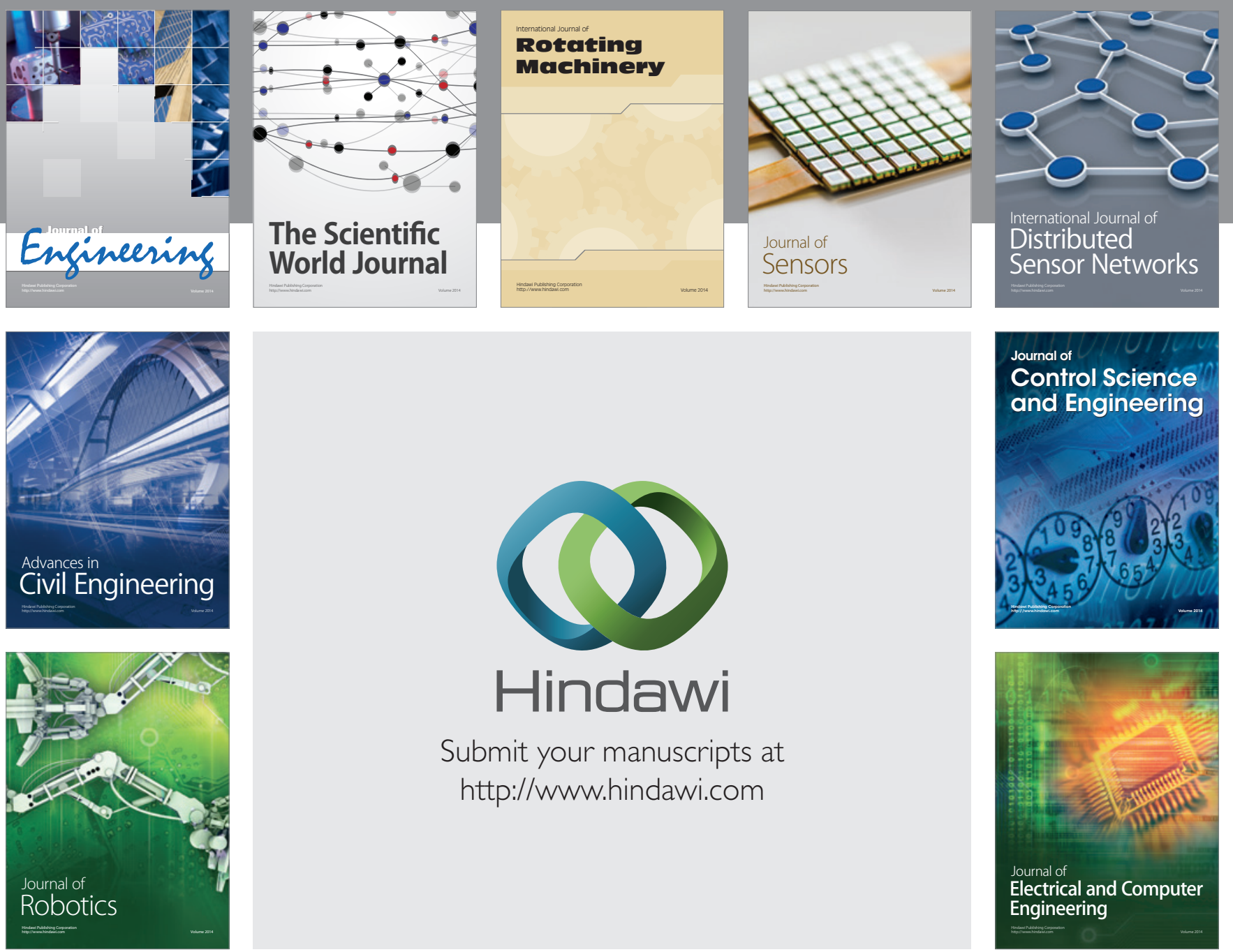

Submit your manuscripts at

http://www.hindawi.com
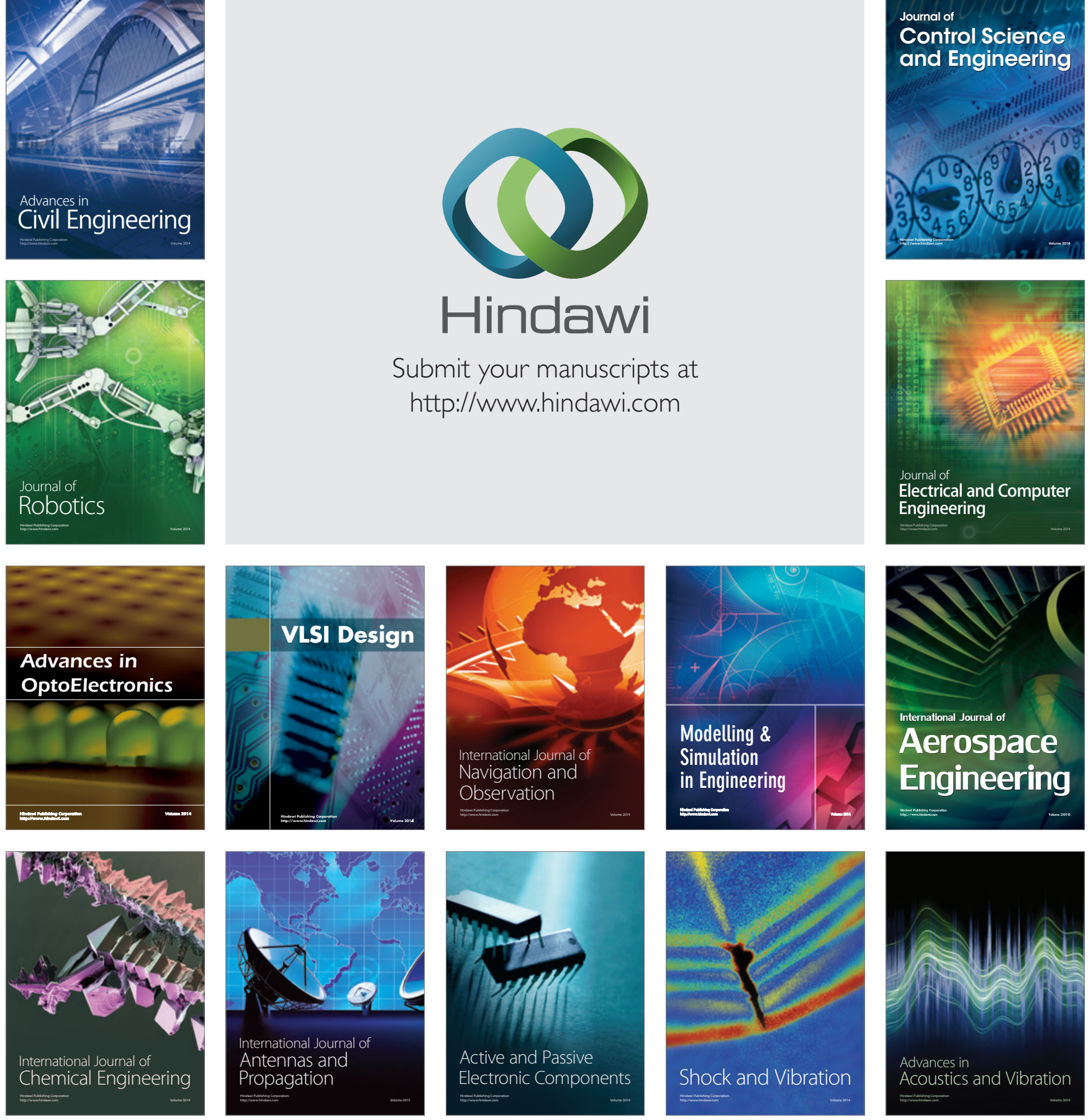